\title{
INNOVACIÓN EDUCATIVA EN LA MODA: ESENCIA, EVOLUCIÓN Y APLICACIONES PEDAGÓGICAS Y CREATIVAS EN EL DESFILE
}

\section{Educational innovation in Fashion: Essence, evolution and pedagogical and creative applications in the runway}

\author{
Laura Luceño CASAls \\ Universidad Politécnica de Madrid \\ Correo-e: laura.luceno@telefonica.net \\ Recibido: II de septiembre de 2020 \\ Envío a informantes: I2 de septiembre de 2020 \\ Aceptación definitiva: 26 de enero de 202I
}

Resumen: El desfile de moda, como acontecimiento social que se ha ido consolidando desde el siglo xix hasta la actualidad, responde a un perfil de espectáculo. El texto se centra en el estudio del mismo, asumido como evento que atesora un doble perfil, profesional y académico. Se parte de una lectura histórico-tipológica y una indagación en la creatividad inherente a su esencia. Asumiendo su naturaleza fundamental, se analiza como fenómeno cargado de creatividad pedagógica, tanto en su acepción profesional, que aporta contenidos formativos a los alumnos asistentes, como esencialmente en el denominado «desfile académico». Esta innovadora versión consiste en que son precisamente los alumnos quienes exhiben sus propias creaciones. Se trata de una dinámica de reciente cuño que se ilustra con un conjunto de casos relevantes extraídos del escenario universitario internacional. La finalidad global del texto es explorar y proponer para su réplica el formato de «desfile académico» como recurso pedagógico de un creciente potencial para la formación de alumnos de Moda.

Palabras clave: moda; innovación educativa; desfile de moda; creatividad. 
AвSTRACT: The fashion runway, as a social and professional event that has been consolidated from the igth century to the present, responds to a show profile. The text focuses on the study of it, assumed as an event that treasures a double profile, professional and academic. It starts from a historical-typological reading, and an inquiry into the creativity inherent to its essence. Assuming its fundamental nature, it is analyzed as a phenomenon loaded with pedagogical creativity, both in its professional meaning, which provides training content to the attending students, and essentially in the so-called «academic runway». This innovative version is that it is precisely the students who display their own creations. This is a recent dynamic, which is illustrated with a set of relevant cases drawn from the international university scene. The overall purpose of the text is to explore and propose for its replication the «academic runway» format as a pedagogical resource with a growing potential for the training of Fashion students.

KEY WORDs: fashion; educational innovation; fashion runway; creativity.

\section{Aproximaciones conceptuales: en torno a la innovación educativa en la Moda}

L

A DOCENCIA UNIVERSITARIA, en general, y la de enseñanzas de Moda, en particular, han experimentado en los últimos tiempos una considerable transformación cualitativa. Desde su génesis institucional, el Espacio Europeo de Educación Superior (EEES) se ideó para poner en marcha un cambio global en las universidades (Zabalza, 2004). El EEes trajo consigo una modificación estructural de títulos, así como un refuerzo de la calidad y la innovación, aplicables a diferentes aspectos, como los propios conceptos educativos y sus consecuencias espaciales (Hernández Díaz, 20I4).

Entre otras directrices de diversa naturaleza, el EEEs promovió en lo pedagógico la progresiva implementación de modalidades innovadoras de enseñanza/aprendizaje (Ruiz y Martín, 2005). Dicha innovación porta en su seno una honda revisión en las actitudes de todos los actores involucrados; de entre ellos, los profesores han de asumir una misión notablemente diferenciada de la desempeñada antaño, debiendo sustituir la tradicional transmisión unilateral de conocimientos por otra multilateral y abierta. De esta forma, el rol del docente pasa a convertirse en un catalizador de metodologías más creativas. Semejante evolución ha acarreado una paulatina reducción del porcentaje de formatos tradicionales, incrementándose propuestas alternativas, cargadas de innovación pedagógica. La razón de ser última de este cambio de paradigma es cumplir otro objetivo asimismo latente en el EEEs: que el aprendizaje se centre en el alumno y pueda, consecuentemente, reforzarse su motivación, como uno de los cimientos de su formación. En efecto, si se efectúa una lectura panóptica de la historia educativa, puede comprobarse que ha tenido lugar una transición evidente: en las fórmulas del ayer, primaba la rigidez espacial y temporal (propias de la lección magistral convencional): «Un primer sentido del espacio escolar lo conceptúa como un mero límite o marco externo de la situación de aprendizaje» (Gairín, 1995, p. 45). Pero se han ido introduciendo pautas cargadas de originalidad, surgiendo tendencias novedosas, caracterizadas por la flexibilidad en las relaciones profesor-alumno, así como en los lugares llamados a albergarlas: «Bajo el nuevo paradigma del aprendizaje, estamos frente a un modelo donde estudiantes diferentes (de diversas edades) aprenden cosas diferentes, de personas diferentes, en lugares diferentes, de modos diferentes y en tiempos diferentes» (Fielding y Nair, 2005, p. I9). 
Tal multiplicidad y versatilidad en las tareas docentes afecta a la configuración del espacio físico donde se realicen, pero exige que los docentes ejerciten la imaginación para dejar atrás su ya obsoleto papel como meros «transmisores» y alternativamente comportarse como «inductores»; bajo esta renovada actitud, serán más capaces de desencadenar la reiterada innovación del estudiante, donde cristaliza la verdadera misión de la universidad. La innovación educativa ha ido impregnando las aulas de todo tipo de titulaciones. En cada una de ellas, las especificidades propias de sus respectivas áreas de conocimiento han influido en cómo se ha realizado todo este proceso. Tan emergente dinámica de comportamiento está dejando una huella relevante en el escenario específico de las enseñanzas de Moda. Se trata de un caso singular que merece ser indagado, por cuanto en su esencia converge la creatividad inherente a su naturaleza como actividad de diseño con la influencia del legado artístico y las sinergias a establecer entre los resultados de aprendizaje y el entorno social, urbano y arquitectónico. Por todo ello, la innovación educativa en Moda, además de compartir las directrices del cambio universitario general, ha introducido sus propias singularidades, lo que justifica la elaboración del presente artículo.

Lo que aprende el futuro diseñador es, como primera valoración, un contenido y unas capacidades que se definen en función de las sinergias para con la sociedad. Por tanto, su formación camina de la mano de la evolución social. Así valorada, la enseñanza de la Moda está supeditada al cambio, y debe ser sensible a su entorno cultural, histórico y urbano (asumido como lugar material donde habita la sociedad).

Analizando la transformación pedagógica que ha experimentado su enseñanza, ha de subrayarse que el Diseño de Moda es una disciplina que incluye asignaturas y pedagogías muy diversas, las cuales requieren espacios asimismo múltiples y diversos. Entre otros, procede mencionar los talleres de confección y patronaje, las aulas de infografía, los laboratorios químico-textiles e incluso los platós donde realizar prácticas de fotografía. La ideación de las futuras colecciones que se exhibirán en pasarelas se nutre de todas las asignaturas del Grado en Diseño de Moda. Desde las más directas, (cual es el caso de Proyectos de Diseño de Moda), pasando por las materias teóricas que fundamentan la inspiración y la investigación creativa (como Historia del Arte, Historia de la Moda o Análisis comparado de Moda), e incluyendo las más científicas relacionadas con la composición de los tejidos o las vinculadas al estudio del mercado, cual es el caso de Márquetin y Gestión del Diseño. Pues bien, la innovación educativa ha consolidado recientemente una modalidad que se ha abierto paso como fórmula espacio-funcional de gran relevancia: el desfile de moda. El presente artículo muestra el potencial formativo de este evento, en sus diferentes acepciones (profesional y académica), ilustrándolo con un conjunto de experiencias llevadas a cabo en los últimos años.

Con el fin de centrar debidamente el marco de análisis, a continuación se describen los rasgos generales del desfile de moda.

\section{El desfile de moda: esencia, historia, tipologías y creatividad}

\section{I. Naturaleza esencial}

El desfile profesional de moda, como espectáculo cargado de expresividad, se ha consolidado como uno de los ritos más importantes de la sociedad contemporánea, 
con trascendencia social y mediática (Finkelstein, 1998). Se celebra dos veces al año, correspondiendo a las colecciones de primavera-verano y otoño-invierno. Su calendario internacional está vinculado a un selecto conjunto de capitales: París, Londres, Milán y Nueva York. Junto a ellas, otras ciudades reivindican un lugar destacado: Berlín, Tokio, Beijing, Madrid, Barcelona, Nueva Delhi, Buenos Aires o Sidney (Breward y Gilbert, 2006). La ubicación del desfile en un enclave específico de la ciudad, la preferencia por una pieza arquitectónica (con valor patrimonial), el diseño del espacio o la escenografía integral son aspectos trascendentales. En el desfile, entendido como espectáculo multidimensional, los diseños de los modistos y el componente arquitectónico se complementan, para realzar valores de marca, sumergiendo al espectador en una atmósfera sugerente, planificada con una intencionada búsqueda de expresividad conjunta. Las fotografías y vídeos que inundarán los medios de comunicación, las redes sociales y las retransmisiones en directo (streaming) son el resultado de la simbiosis entre el marco arquitectónico y la estética de la colección, resultando todo ello unificado en un ambiente de expresividad múltiple (composición formal, estética, luz, sonido, etc.). Ha de reiterarse que la arquitectura juega un papel clave en la construcción de las imágenes del desfile y en la narrativa de la colección; pero no pueden obviarse otros elementos expresivos indispensables (música e iluminación), si bien no se analizan a fondo en este texto.

\subsection{Evolución bistórica}

\subsection{Origen}

Los desfiles de moda pueden analizarse bajo una aproximación histórica (Marshall, 1978; Quick, 1997; Grumbach, 2006). Una aproximación que, desde diversas ópticas científicas, se ha vinculado a la cultura (English, 20I3). Los desfiles vieron la luz cuando se diferenciaron confección y alta costura (Luceño, 20I8). Todo empezó en París, a finales del xIx, con Charles Frederick Worth, que entendió la moda como arte. Se consideraba a sí mismo un artista, mostrando sus creaciones bajo una atmósfera expresiva, como si se tratara de la inauguración de una exposición de arte. Worth firmaba sus trajes, como los pintores sus lienzos. Con él nació la etiqueta rubricada, que cosía en las prendas: «El origen de los desfiles de moda se atribuye a Charles Frederick Worth hacia 1870 en París y de allí se expandieron por Londres (I890) y Nueva York (I910). Será después de la Primera Guerra Mundial cuando se convertirán en verdaderos acontecimientos sociales que ilustrarán las revistas de moda» (Evans, 2007, p. 29). El segundo momento trascendental para entender la pasarela data de I9or, cuando Lady Duff-Gordon modificó el desfile habitual. Para rentabilizar más las nuevas propuestas de su salón de costura (llamado Lucile), decidió presentar sus prendas en un teatro, titulando la colección Gowns of emotions; el desfile se ideó como un espectáculo con proscenio, telón, música, iluminación, invitaciones, programas y poses teatrales (Schweitzer, 2008). A partir de 1903, el desfile dejó de ser un evento elitista destinado solo a las compradoras de la alta costura, para convertirse en una muestra más pública, celebrada en grandes almacenes. Desde entonces, el desfile compaginaría la faceta comercial con su identidad como espectáculo expresivo y artístico. 
INNOVACIÓN EDUCATIVA EN LA MODA: ESENCIA, EVOLUCIÓN

2.2.2. El desfile elevado

El desfile de moda todavía no fue una convocatoria abierta a los medios de comunicación, hasta que en I9ıo Paul Poiret invitó a diversos periodistas. Las pasarelas empezaron a difundirse en los noticiarios franceses, Pathé o Gaumont, antes de que se iniciase la proyección de la película correspondiente. Como tipología formal, el desfile longitudinal elevado surgió en 1908, en el gran almacén Wanamaker de Filadelfia (Entwistle y Wissinger, 20I2). La transformación tipológica supuso un cambio de paradigma no solo en la dimensión espacial, sino en la social. Los desfiles pasaron a atraer a distintos colectivos, como actores y personajes vip. Antes de la Primera Guerra Mundial, se comparaba la pasarela con el espectáculo del music-ball. Pero en I923 se generalizó su difusión, acogiendo a periodistas y clientes, a quienes se agasajaba con champán y pequeños obsequios, como pintalabios. La prensa de la época se refería ya a los desfiles en clave arquitectónica, como espacios con dignos salones e imponentes escalinatas. El formato elevado continúa hoy siendo muy utilizado, tanto en la versión profesional como en la dinámica de innovación educativa inherente al «desfile académico» realizada como por estudiantes, como se analizará más adelante.

\subsubsection{De las presentaciones de alta costura al desfile-happening}

Desde 1948, los desfiles diversificaron su perfil. Buscando un efecto sorpresa, se añadieron recursos de humor (gags), que aportaban diversión, ofreciendo dosis de innovación visual. A finales de los 50, la incipiente revolución juvenil anunciaba una nueva etapa. Mary Quant quiso que las modelos bailaran y corriesen a lo largo del recorrido; en 1956, presentó en el Hotel Crillon 60 trajes en I5 minutos. El creciente énfasis en la performance global provocaría un asentamiento del desfile elevado, como tipología que ensalzaba espacialmente las colecciones y facilitaba la visión de los asistentes. Con la revolución juvenil y el fenómeno antimoda apareció el desfile-bappening. Paco Rabanne, arquitecto de formación, introdujo en 1966 una innovación, al proponer «I2 vestidos inllevables» en el Hotel Georges V. Empleaba materiales alternativos, como plásticos o metal, añadiendo una actitud inexpresiva en las modelos (quienes no debían sonreír). Los desfiles evolucionaron, buscando nuevos enclaves. Pierre Cardin decidió desfilar en plena calle de París; las salas tradicionales se reemplazaron por clubes nocturnos y discotecas, como Bus Palladium o el Crazy Horse Saloon. La música de los desfiles dejó de ser un ingrediente secundario para adquirir un marcado protagonismo. Paralelamente, se oscurecía el patio de butacas (seating) para iluminar solamente la pasarela. En esa época, el fenómeno boutique o concept store, denominado swinging London en la revista Time, se vio reflejado en la evolución de los desfiles, que se alojaban en los escaparates de las modernas boutiques. En 1967, el desfile había ya cobrado tal importancia expresiva que nació la profesión de escenógrafo, encargado de crear las atmósferas adecuadas. En los 70, se apostó por la originalidad, recurriendo a la arquitectura como aliada. Kenzo desfiló en 1972 dentro de una estación de ferrocarril, la Gare d'Orsay. París, capital indiscutible de la moda hasta el momento, empezó a perder protagonismo frente a Londres o Nueva York. Para reinventarse, ubicaría sus pasarelas en lugares emblemáticos, como el Museo del Louvre. Las presentaciones de los japoneses Yamamoto y Kawakubo en 1982 su- 
pusieron una revolución integral: sus modelos desfilaban con la cara blanca y lívida, no sonreían y se desplazaban con grandes zancadas. La música era tenue, disonante, lenta, distinta a todo lo anterior. Las presentaciones evolucionaron hacia eventos sublimes, cargados de poesía y minimalismo. Los 8o trajeron en Japón la masificación, bastando con adquirir una entrada para asistir; en cambio, en el escenario occidental, se exigía una invitación personal. En 1984, Mugler organizó un desfile en el Zénith, una expresiva pieza arquitectónica multiusos, situada en el vanguardista Parque de la Villette. Finalmente, en 1985 la moda se alojó en un museo, el Musee d'Art Contemporain de Burdeos, con la colección de Azzedine Alaïa.

\subsubsection{Tendencias recientes: virtualidad versus presencialidad}

En los 9o, los avances tecnológicos impulsaron la transformación de los desfiles (Volino y Thalmann, 2000). En 1995, la tendencia virtual hizo de firstview la primera página web dedicada a difundir desfiles. Walter Van Beirendonck hizo interactuar a sus modelos con imágenes de ordenador y en 1997 una discoteca proyectó un desfile virtual sobre una gran pantalla, año en que se inauguró Fashion TV. En sentido opuesto, surgió una corriente que reivindicaba el espacio físico como aliado para incrementar la expresividad de los desfiles, que empezaron a decantarse por obras singulares de arquitectura (añadiendo así su valor patrimonial, artístico y estético). Un ejemplo fue la Fundación Cartier, diseñada por Jean Nouvel, que albergó un desfile en 1995. En Bélgica, la llegada de Los seis de Amberes supuso una actitud transgresora, en su estilo y en el recurso a espacios alternativos, pues ubicaron sus desfiles en solares abandonados, garajes y fábricas no rehabilitadas. Rompían así con la composición lineal del desfile, de modo que las modelos deambulaban, zigzagueando sin seguir las directrices tradicionales de circulación. En el formato de desfile-performance, Galliano ideó en 1998 para Dior un desfile en la Gare D'Austerlitz, donde las modelos entraban y salían de los vagones. Yves Saint Laurent mostró sus diseños en la inauguración de otra emblemática obra, el Stade de France, donde las modelos se elevaban sobre el suelo mediante grúas. Alexander McQueen creó presentaciones impactantes. El innovador modisto no entendió estos eventos como una fiesta, sino que buscó reacciones extremas, que convulsionaran al espectador; junto con Galliano, ideó desfiles memorables (Bolton, 20II). Al margen de otras tendencias recientes, como la conocida tipología del «espacio negro» o el «espacio blanco» anodino, asimilable a una caja vacía, hoy el eclecticismo parece haberse asentado en las pasarelas, donde se mezclan elementos de varios periodos y etapas, resultando una dimensión estética global, espectacular y expresiva, que atesora en paralelo un gran potencial formativo para los alumnos de Moda. En los actuales tiempos de pandemia, numerosas marcas han optado por presentar sus nuevas colecciones en novedosos soportes y canales, a modo de fashion films, como por ejemplo la colección para hombre Otoño-Invierno 202I de Louis Vuitton, o bien simulando la estética del videojuego en lugar del desfile tradicional, en el caso de Balenciaga. Probablemente la más original haya sido la presentación de Moschino, que en la temporada Primavera-Verano 202r ha simulado el habitual desfile de moda en el que tanto los espectadores (famosos y periodistas que suelen sentarse en la primera fila) como las modelos eran marionetas. El diseñador Jeremy Scott probablemente se haya inspirado en las muñecas Pandora que viajaban desde París a las 
cortes europeas en los siglos XVII y XVIII, ataviadas con las nuevas propuestas, o en el Teatro de la moda que escenificó, con muñecas de alambre, las colecciones de los y las mejores modistas de la alta costura parisina, ante las dificultades generadas después de la Segunda Guerra Mundial. En situaciones complejas y adversas, la moda siempre ha buscado respuestas imaginativas; y esa es una de las interesantes lecciones que pueden sacar los estudiantes.

Tras revisar la evolución histórica de los desfiles, pueden clasificarse conforme a una serie de formatos espaciales diferentes.

\subsection{Formatos espaciales del desfile de moda}

\subsection{Pautas compositivas básicas}

Existe un conjunto de pautas formales básicas en los desfiles, extraíbles de la tradición compositivo-arquitectónica general (Clark y Pause, 1984): lineal (en sus acepciones unidireccional y bidireccional), rectangular, circular, centrada, aleatoria u orgánica.

Bajo otro enfoque, pueden desglosarse en desfiles interiores o exteriores. Los interiores se alojan en piezas arquitectónicas, que añaden su valor patrimonial; algunos recrean ambientes exteriores (desfiles de Chanel en el Grand Palais). En otras ocasiones, se inspiran en temáticas diversas, como los 4 elementos: aire (Chalayan, 2009), agua (McQueen, Walking on Water, 1997), tierra (Dior, Montañas de flores, 2016) y fuego (McQueen, Ring of Fire, 1998). Los desfiles exteriores han ido ganando presencia paulatinamente. Se adaptan morfológicamente a los entornos urbanos, tanto si son piezas patrimoniales (Chanel Colección Métiers d'Art, en exteriores del palacio escocés de Linlithgow, 20I3; Fendi, en la Muralla China, 2007), como si son espacios libres naturales (Pierre Cardin, desierto chino de Dunhuang, 2008) u otros insertos en la trama ciudadana. Dentro de estos últimos, los desfiles urbanos constituyen un evento multidimensional de proyección de la moda hacia el contexto social (Chanel, Playa del Lido, 2oro; Adolfo Domínguez, casco antiguo de Orense, 20I9, etc.). Esta tipología es muy útil para los denominados «desfiles académicos», donde se exponen diseños de alumnos, tal y como se analizará en próximos epígrafes del presente artículo. La moda se abre a la ciudad, que adquiere así rango de aula innovadora (Pérez y González, 2010).

\subsubsection{Desfile, espacio abierto y escenografía}

Los desfiles urbanos más impactantes son aquellos inspirados en la cultura del lugar; una cualidad compartida con otras disciplinas artísticas (Bourdieu y Johnson, 1993). Este rasgo es portador de contenidos formativos para alumnos de Moda, como se justificará más adelante. Durante su evolución, los desfiles se han ido orientando progresivamente hacia nuevos públicos, abriéndose a la ciudad; como ejemplo ya recordado, Pierre Cardin presentó su colección en las calles parisinas. Si Galliano y $\mathrm{McQueen}$ crearon desfiles espectaculares interiores, Karl Lagerfeld ha sido la gran estrella de los exteriores. Sus recordadas colecciones para Fendi y Chanel tuvieron lugar 
en la muralla de China, en la playa del Lido en Venecia, en los Jardines de las Tullerías o en el escocés castillo de Linlithgow. Otra tendencia creativa fue la recreación de lugares artificiales. El diseñador expone su colección en un marco espectacular, buscando emocionar al asistente. Como se ha recordado anteriormente, McQueen trabajó con los cuatro elementos naturales, haciendo desfilar a sus modelos por una pasarela de agua o dentro de un círculo de fuego. Lagerfeld imaginó para Chanel escenografías grandilocuentes, como un iceberg de 240 toneladas en el Grand Palais, una jungla de papel o la recreación de una protesta feminista en calles parisinas... Son testimonios de la vocación expresiva que ha distinguido a numerosos desfiles impregnados de fantasía, que demuestran el enriquecimiento creativo del que pueden beneficiarse los alumnos de Moda que las experimenten.

\subsection{Desfile y creatividad}

Deben subrayarse algunos casos de excelencia en la colaboración entre moda y arquitectura, en clave de expresividad compartida: «Hoy en día, la relación entre arquitectura y diseño de moda no es algo fuera de la mente e imaginario» (Farahat, 20I4, p. 3). Ya se ha señalado que el desfile responde a un perfil multidimensional (espacial, estético, lumínico y musical), que refuerza sus misiones básicas: ser una potente herramienta de marketing; fidelizar al cliente y grabarse en la memoria del espectador. El desfile, como expresión creativa, es el evento universal de la moda (Duggan, 2006). Transmite emoción y vitalidad, adquiriendo rango de obra de arte (Skov, Skjold, Moeran, Larsen y Csaba, 2009) y habiendo sido calificado como «Arte de la puesta en escena» (Theunissen, 2006). El desfile fusiona moda y arquitectura, en clave de creatividad, y ofrece un ingente contenido formativo al estudiante que la experimenta, pues ambas disciplinas comparten temas diversos, como ritmo, composición, textura, color, volumen, ornamento, transparencia, movimiento o luz (Campos y Luceño, 20I8).

Una vez efectuada la lectura sobre historia y formatos del desfile, seguidamente se definen las cualidades que hacen de él un elemento cargado de innovación educativa para la enseñanza de la Moda.

\section{El desfile como elemento de innovación educativa en moda}

\section{I. La versión profesional como escenario docente}

La primera acepción pedagógica es la derivada de la versión profesional de los desfiles. Se localizan en contenedores arquitectónicos urbanos, normalmente recintos feriales o edificios singulares (museos, teatros, almacenes, antiguas instalaciones industriales, etc.). Cuando un docente de Moda programa que sus alumnos asistan a dichos desfiles profesionales, propicia una innovación pedagógica dual: por un lado, que aprendan a partir de la experiencia in situ derivada de la asistencia a un espectáculo impregnado de expresividad, contemplando en directo la presentación de las últimas colecciones diseñadas por modistos; por otro, se desplaza a un espacio físico alternativo al aula convencional, beneficiándose así del valor formativo que toda ciudad ofrece a las universidades. Esta acepción implica la participación directa de los profesionales 
de la moda (ajenos a la universidad), quienes actúan, de algún modo, como profesores para el alumno, lo que refuerza su motivación para aprender. Por otro lado, los desfiles se celebran en establecimientos insertos en áreas urbanas, dentro de edificios con valor patrimonial, lo que añade el interés derivado del conocimiento in situ de esas piezas arquitectóncias. En otras palabras, el estudiante aprende de modos diferentes en lugares diferentes. Al asistir a un desfile profesional de moda, se sumerge en una experiencia formativa alternativa, donde el desfile como tal comparte su rol expositivo con otro, en clave de escenario pedagógico o aula innovadora.

\subsection{El «desfile académico»}

\subsection{Rasgos básicos}

En la moda, se ha consolidado una modalidad formativa de gran interés: el «desfile académico». Fruto de la fusión entre la innovación educativa inherente al EEEs y la pasarela profesional, dicho «desfile académico» consiste en la celebración durante el curso académico de un evento de esta naturaleza, pero protagonizado por los alumnos. Bajo la orientación de los profesores y coordinadores, los estudiantes exhiben el fruto de su aprendizaje, mediante la puesta en escena de sus diseños en escenarios similares a los profesionales. Dicha similitud se fundamenta en dos características básicas: la propia exhibición en un formato multidimensional de las colecciones; y la celebración del mismo en edificios pertenecientes al entorno urbano y alternativos a los espacios habituales de su centro educativo. Por ello, esta innovadora dinámica se beneficia además del interés patrimonial del lugar elegido para el desfile.

Tras esta somera descripción del «desfile académico», seguidamente se procede a analizar un conjunto de experiencias nacionales e internacionales, en las que se ha puesto en práctica.

\subsubsection{Analogías y herencias pedagógicas}

A modo de consideración global, debe anotarse que los desfiles, en su acepción académica, son un fenómeno universitario reciente; por tanto, no es fácil disponer de estudios o referencias científicas sobre su dimensión pedagógica. Sin embargo, y debido a que poseen un cierto perfil de simulación de actividad profesional, sí pueden incluirse dentro de un escenario afín, aunque perteneciente a otras áreas de conocimiento. Existe una amplia gama de aplicaciones de dicha simulación; entre otras, cabe recordar las empleadas en Derecho (González, Álvarez, Pérez, Álvarez, Sanjurjo y Fernández, 20Io) o Medicina (Maneru, 20I2), dentro de un marco genérico que remite a la simulación como estrategia didáctica (Sánchez, 2013). Uno de los rasgos que comparten todas estas iniciativas es que comprometen una actividad directa y personal del alumnado. La diversidad de actividades que propician tiene su centro de gravedad en el estudiante, quien gracias a las simulaciones alcanza un grado de motivación de gran relevancia. Todo ello entronca con el pasado lejano, como bien se comprueba al revisar determinadas características de la Ratio Studiorum que diseñaran los jesuitas (Martín, 20II). Entre otros recursos, los pedagogos de la Compañía hicieron énfasis 
en la escenificación de corte teatral como eficaz aliado educativo (Klein, 2002; Kolvenbach, 1993). Pues bien, los «desfiles académicos» comparten desde la contemporaneidad no pocos principios pedagógicos con las preexistencias descritas, pues inducen a una metamorfosis sutil de la versión profesional, convirtiéndola en un evento de origen y destino pedagógico.

3.2.3. Experiencias recientes de «desfile académico»: innovación educativa en la praxis

Los «desfiles académicos», donde los estudiantes de Moda se erigen en centro del proceso educativo, tienen lugar en entornos urbanos singulares, lo que añade el ya mencionado valor formativo derivado de la valía estética, histórica o patrimonial del edificio o el enclave de que se trate. En instituciones españolas e internacionales, se han llevado a cabo diversas experiencas de este perfil que comparten la esencia del formato pedagógico innovador. De entre otras, pueden considerarse como excelentes representantes de esta tendencia las siguientes: Pozuelo de Alarcón (UPM-Montegancedo), Culver City (OTIS), Melbourne (RMIT), Madrid (CSDMM-Distrito Centro), Florencia (Istituto Marangoni), Kannur (NIFT) y Nueva York (FIT).

Pozuelo de Alarcón (UPM-Montegancedo). El Centro Superior de Diseño de Moda de Madrid (CSDMM), adscrito a la Universidad Politécnica de Madrid (UPM), posee su sede central en el Campus Sur, situado en la periferia oriental de la capital. En 20I4, se realizó un «desfile académico» teñido de innovación. El lugar elegido, ajeno a su recinto central, fue el Campus de Montegancedo que la propia UPM posee en la localidad de Pozuelo de Alarcón. Dentro del mismo, el «desfile académico» se ubicó en una instalación verdaderamente singular: el túnel de viento, un equipamiento técnico del Instituto Universitario de Microgravedad Ignacio Da Riva. La puesta en escena de los diseños de los alumnos de $4 .^{\circ}$ curso del Grado en Diseño de Moda alcanzó unas cotas de expresividad muy elevadas, pues las modelos avanzaban contra el fuerte viento generado en el túnel, lo que producía un llamativo efecto de plasticidad estética.

Culver City (Otis.). El Otis College of Art and Design, ubicado en Culver City (urbe californiana próxima a Los Angeles, EE. UU.), alberga en su seno el Otis College Fashion Design Department. En 2019, se celebró un «desfile académico» que tuvo como escenario (por segundo año consecutivo) el Elaine and Bram Goldsmith campus en Westchester. Como singularidad de este evento, los estudiantes de Moda compartieron espacio y tiempo expositivo con diseñadores consagrados. La razón que justificó esta modalidad mixta (profesional-académica) es porque los fondos generados por el evento se destinan a financiar becas estudiantiles. La pasarela incluyó más de i25 creaciones de alumnos de la institución.

Melbourne (RMIT). En 2019, el Royal Melbourne Institute of Technology organizó un evento que respondió al perfil de "desfile académico», donde veinte alumnos del Bachelor of Fashion exhibieron en público sus diseños. La pasarela, de periodicidad anual, se denomina Melbourne Fashion Week's student runway. El lugar elegido para albergarlo fue el Town Hall, una pieza arquitectónica decimonónica situada en 
INNOVACIÓN EDUCATIVA EN LA MODA: ESENCIA, EVOLUCIÓN

el área central de la ciudad, entre las calles Swanston y Collins. Como rasgo innovador añadido de esta pasarela, ese año 2019 se optó por ampliar el ámbito geográfico y académico, pues se invitó a otra institución foránea. Trascendiendo las fronteras de Australia, participaron también estudiantes del Ueda College of Fashion de Osaka (ciudad japonesa hermanada con Melbourne). Con ello, la innovación educativa adquirió una dimensión internacional, integrándose los diseños elaborados por alumnos de la misma disciplina, pero provenientes de distintas culturas.

Madrid (CSDMM-Distrito Centro). El ya mencionado Centro Superior de Diseño de Moda de Madrid (CSDMM), adscrito a la UPM, celebró en 2017 un «desfile académico» en un enclave urbanístico-arquitectónico singular, fuera de su sede central del Campus Sur. La pasarela tuvo lugar a lo largo de los viales anexos al Cuartel del Conde Duque, situado en el Distrito Centro de Madrid. Como claves añadidas de innovación pueden subrayarse las siguientes: se ubicó dentro de un valioso escenario patrimonial, polarizado por el mencionado cuartel (diseñado como instalación militar en 1717 por Pedro de Ribera y reformado por Julio Cano en 198i para albergar el nuevo uso cultural); y el hecho de que los trabajos de los alumnos se proyectaron sobre las áreas adyacentes, expresando la vocación de la moda de salir al encuentro de la sociedad.

Florencia (Istituto Marangoni). El prestigioso Istituto Marangoni, que posee sedes en Milán, París, Londres, Bombai y Miami, organizó en 2019 un expresivo «desfile académico», desplegado sobre una de las arterias del casco histórico florentino, la Via Tornabuni. Los alumnos del $3 .{ }^{\text {ER }}$ curso del Programa en Fashion Design del Istituto Marangoni expusieron sus diseños a lo largo de tan emblemática vía, donde la entidad tiene su sede (el Palazzeto Tornabuoni, que data del siglo XVIII). Para la pasarela, se dispuso una superficie de madera que realzó el recorrido lineal, encontrando a su paso una secuencia arquitectónica de gran atractivo: las fachadas de varios Palazzos, que fueron engalanadas para la ocasión (Larderel, Viviani dell Robbia y Strozzi). Al celebrarse el «desfile académico» en un contexto urbano de tan elevada carga estética como la Via Tornabuoni, el Istituto Marangoni logró que la proyección de los resultados de aprendizaje de sus estudiantes se efectuase de modo singular e intenso sobre el contexto sociourbano.

Kannur (NIFT). El campus del National Institute of Fashion Technology está situado en la localidad india de Kannur. En su seno, se celebró en 2016 un evento orientado a exhibir las colecciones elaboradas por los alumnos. Los diseños, caracterizados por una notable creatividad textil, tenían un carácter académico, pues formaban parte de los trabajos exigidos para alcanzar su graduación. La puesta en escena estuvo compuesta por las creaciones de los estudiantes del Master's of Design, Fashion Management and Bachelor's of Textile Design, Fashion Technology and Knitwear Design. El «desfile académico», celebrado en Mangattuparambain Kannur, se desarrolló durante 2 jornadas, a lo largo de las cuales los proyectos de 87 alumnos pudieron ser conocidos por el público general. Al interés en materia de diseño formal de los trabajos académicos se sumó la aplicación de las más modernas tecnologías. 
INNOVACIÓN EDUCATIVA EN LA MODA: ESENCIA, EVOLUCIÓN Y APLICACIONES PEDAGÓGICAS Y CREATIVAS EN EL DESFILE LAURA LUCEÑO CASALS

Nueva York (FIT). El reconocido Fashion Institute of Technology tiene su sede principal en el área urbana central de Manhattan. Esta institución celebra con regularidad pasarelas académicas, donde los alumnos muestran sus colecciones. Como ejemplo, puede mencionarse la celebrada en 2017, denominada Future of Fashion Runway Show. Los diseños pusieron de manifiesto el excelente nivel de creatividad alcanzado por los estudiantes del FIT, como institución que les formó empleando sus recursos de investigación, experimentación, pensamiento crítico y competencia artística. A los rasgos innovadores propios de este tipo de eventos, donde convergen la multidimensionalidad espacio-temporal y la naturaleza pedagógica, se sumó recientemente un aspecto obligadamente innovador, muy vinculado al contexto social del momento. En 2020, el referido «desfile académico» hubo de amoldarse a un formato virtual, debido a las consecuencias derivadas del COVID-19. En consecuencia, tuvo que realizarse de manera virtual, si bien se logró (pese a semejante limitación) dar a conocer los diseños de moda realizados en el FIT.

Valgan los casos de estudio descritos como testimonios del reciente fenómeno del «desfile académico», cuya implementacion en la esfera universitaria está paulatinamente creciendo en el panorama nacional e internacional de las enseñanzas de Moda.

\section{Conclusiones}

Tras haber expuesto en epígrafes precedentes un elenco de contenidos esenciales, enmarcados dentro de un escenario global de innovación educativa, puede extraerse un conjunto de conclusiones y esbozar ciertas proyecciones futuras, así como posibles extrapolaciones a otras disciplinas. En lo que atañe a las enseñanzas de Moda, el desfile se revela como evento con un considerable potencial de innovación en materia pedagógica. Y lo hace en sus dos versiones básicas: la profesional y la protagonizada por alumnos -el «desfile académico»-, que constituye el núcleo del presente artículo.

Respecto a su primera acepción, es pertinente observar que la innovación educativa no siempre exige la puesta en práctica de una metodología inédita dentro del aula; en ocasiones, consiste en proponer al alumno una experiencia real, profesional y profesionalizante, que se encuentre fuera del recinto habitual. Los enclaves donde tienen lugar estos eventos están habitualmente compartidos con el patrimonio de la ciudad; esta circunstancia suministra unas ingentes posibilidades como localizaciones dinámicas y transgresoras, de potente proyección sociourbana; están cargadas así de una expresividad añadida, debido a la naturaleza intrínsecamente creativa de la urbe (Landry, 2000; Carta, 2007). La pasarela, como acontecimiento estelar de la moda, es un evento multidimensional que ha dejado un repertorio de manifestaciones muy variadas a lo largo de su devenir histórico. La prolífica herencia de la creatividad aplicada a los desfiles demuestra que se pueden transmitir sensaciones que impacten en las emociones de los asistentes y -en el caso de los alumnos- inspiren su futura labor profesional. Por todo ello, la asistencia a los mismos tiene como resultado formativo que el estudiante adquiera conocimientos derivados de la contemplación in situ de las últimas creaciones de los modistos profesionales.

En lo que atañe a la segunda acepción, el presente texto defiende el interés del denominado «desfile académico». Se trata de una estrategia que ya ha generado un variado repertorio de casos dentro y fuera de España (alguno de los cuales se ha descrito 
en epígrafes precedentes). Es claramente tributaria de la innovación educativa, pues apuesta por dar visibilidad a los trabajos pedagógicos de los estudiantes de Moda. Impulsada desde el profesorado y la dirección del centro educativo que corresponda, constituye un formato de alto interés pedagógico, donde convergen diversas cualidades: por un lado, exponen resultados directos de aprendizaje, mediante una puesta en escena que emula los eventos profesionales; en segundo término, promueven la combinación de creatividades diversas, como la inherente al diseño de las colecciones y la ideación de la escenografía del acto; en tercer lugar, se ubican en emplazamientos externos al recinto universitario, lo que introduce otro factor de innovación, derivado del uso de espacios alternativos al aula o taller convencional; finalmente, y como derivada de la circunstancia anterior, añaden el valor formativo (patrimonial, estético o cultural) que atesoran los edificios o entornos donde se celebren estos eventos.

A partir de la valía del «desfile académico» como modalidad innovadora de enseñanza/aprendizaje, una mirada al futuro descubre que este se muestra incierto, pero prometedor. En moda, la lectura de los ejemplos de excelencia pasados puede ser una extraordinaria fuente de creatividad futura. A modo de reflexión global, cabe recordar lo que señalaba el arquitecto y escultor Juan Bordes: «Una obra maestra no vive de su pasado, sino que es una suma interminable de lecturas históricas» (Bordes, 2006, p. I6). Al hilo de tan sugerente reflexión, puede concluirse que, si se recibe el impulso de la emergente dinámica de innovación del «desfile académico», es factible generar una cadena de creatividad que alimente la formación en moda. A tenor del rasgo material de las pasarelas, debe mencionarse una tendencia reciente: la deriva virtual. Semejante sesgo podría cambiar el futuro de eventos de esta naturaleza (recogiendo ciertas tendencias previas a la pandemia en algunos diseñadores), dando oportunidad a su supervivencia (algo que las consecuencias del COVID-r9 parecen acentuar). Pero, frente a dicha tendencia (original o inducida por la situación sanitaria internacional), es tiempo de proclamar que dicha tendencia online nunca podrá reemplazar la experiencia personal de crear y asistir a una pasarela real (tanto en su versión profesional como en la académica), donde se potencian al unísono los sentidos y emociones. Una reflexión extrapolable, por otro lado, a todo tipo de docencia.

Puede concluirse con una última valoración, afirmando que el «desfile académico» optimiza el hecho pedagógico, inspira creatividad y refuerza la visibilidad de los resultados formativos de los estudiantes.

\section{Bibliografía}

Bolton, A. (20II). Alexander McQueen. Savage beauty. Nueva York: Metropolitan Museum of Art.

Bordes, J. (2006). La infancia del artista o las fuentes de Nilo. Discurso de Juan Bordes Caballero. Madrid: Real Academia de Bellas Artes de San Fernando.

Bourdieu, P. y Johnson, R. (1993). The field of cultural production: Essays on art and literature. Cambridge: Polity Press.

Breward, C. y Gilbert, D. (2006). Fashion's world cities. Oxford: Berg Publishers.

Campos, P. y Luceño, L. (20I8). Comparación didáctica entre arquitectura y moda: experiencias docentes innovadoras y espacios asociados. Revista Iberoamericana de Educación Superior-RIES, 26 (IX), I53-I70. 
INNOVACIÓN EDUCATIVA EN LA MODA: ESENCIA, EVOLUCIÓN Y APLICACIONES PEDAGÓGICAS Y CREATIVAS EN EL DESFILE LAURA LUCEÑO CASALS

Carta, M. (2007). Creative City. Dynamics, innovations, actions. Trento: LISt Laboratorio Internazionale Editoriale.

Clark, R. y Pause, M. (1984). Arquitectura: temas de composición. Barcelona: Gustavo Gili.

Duggan, G. G. (2006). The Greatest Show on Earth: A look at contemporary fashion shows and their relationship to performance art. In J. BRAnd y J. Teunissen (eds.), The Power of Fashion: About Design and Meaning (pp. 222-248). Arnhem: Terra and ArtEZ Press.

ENGLish, R. (2013). A cultural history of fashion in the 2oth and 2Ist centuries. Londres: Bloomsbury Publishing.

EntWistle, J. y Wissinger, E. (eds.). (2012). Fashioning models. Image, text and industry. Londres: Berg.

Evans, C. (2007). Fashion show. Les desfilades de moda. Barcelona: Ajuntament de Barcelona.

FARAHAT, B. I. (20I4). The interrelationship between fashion and architecture. Proc. Al-Azhar Engineering $\mathrm{I}^{\mathrm{TH}}$ International Conference, Egypt, Cairo, Vol. 9, No. 6, pp.I- I7.

Fielding, R. y Nair, P. (2005). The language of school design. Minneapolis: Designshare.

Finkelstein, J. (1998). Fashion. An introduction. Nueva York: New York University Press.

Gairín, J. (1995). El reto de la organización de espacios. Aula de Innovación Educativa, 39, 45-50.

González, P.; Álvarez, P.; Pérez, G.; Álvarez, C.; Sanjurjo, E. y Fernández, G. (20io). Acción pedagógica de simulación de juicios. REJIE: Revista Jurídica de Investigación e Innovación Educativa, 2, 8I-92.

Grumbach, D. (2006). Une histoire institutionelle des défilés de mode. En Musée Galliera (ed.), Showtime: Le Défilé de la Mode (pp. I29-I46). París: Paris Musées.

Hernández Díaz, J. M. (20I4). Los espacios de la universidad española. Una lectura histórica. CIAN-Revista de Historia de las Universidades, $I 7(\mathrm{I})$, 8I-IOO.

Klein, L. (2002). Actualidad de la pedagogía jesuita. México: ITEso.

Kolvenbach, P. (1993). A pedagogia inaciana hoje. Discurso do P. PeterHans Kolvenbach aos membros do grupo de trabalho sobre Pedagogia inaciana. Uma proposta prática (Villa Cavalletti, 29.4.1993). En Pedagogia inaciana. Uma proposta prática, Loyola, São Paulo, pp. 89115.

LANDRy, C. (2000). The creative city. A toolkit for urban innovators. Londres: Earthscan Publication Ltd.

Luceño, L. (20r8). Estudio de las paradojas de la moda. Study of the paradoxes of fashion. dObra[s]. Revista da Associação Brasileira de Estudos de Pesquisas em Moda, 24(II), I88-20I.

Maneru, G. (20I2). La adquisición de habilidades y competencias en el Centro de Simulación Médica. Revista Internacional de Humanidades, I(2), 198-215.

Marshall, C. (1978). The cat-walk. Londres: Hutchinson.

Pérez, M. y González, D. (20Io). Salir del aula: el papel de la ciudad en la educación. Tejuelo, 9, I2I-I35.

Quick, H. (1997). Catwalking. A history of the fashion model. Londres: Hamlyn.

Ruiz, C. y Martín, C. (2005). Innovación docente en la Universidad en el marco del eeEs. Educatio Siglo XXI, 23, I71-I89.

Sánchez, M. (2013). La simulación como estrategia didáctica: Aportes y reflexiones de una experiencia en el nivel superior. Párrafos Geográficos, I2(2), 55-60.

Schweitzer, M. (2008). Patriotic acts of consumption: Lucile (Lady Duff Gordon) and the Vaudeville fashion show craze. Theatre Journal, 60(4), 585-608. Johns Hopkins University Press.

Skov, L.; Skjold, E.; Moeran, B.; Larsen, F. y Csaba, F. (2009). The Fashion show as an art form. Creative Encounters. Copenhage: Copenhagen Business School.

Theunissen, J. (2006). From dandy to fashion show: fashion as performance art. En J. Brand y J. Teunissen (eds.), The power of fashion (pp. 194-222). Arnhem: Terra and ArtEZ Press.

Volino, P. y Thalmann, N. (2000). 3 D Fashion design and the virtual catwalk. En J. A. Vince y R. Earnshaw (eds.), Digital media: The future (pp.I6o-174). Londres: Springer.

Zabalza, M. (2004). Innovación en la enseñanza universitaria. Contextos Educativos, 6-7, II3-I36. 